University of Nebraska - Lincoln

DigitalCommons@University of Nebraska - Lincoln

Faculty Publications from the Harold W. Manter Laboratory of Parasitology

$2-1980$

\title{
Ultrastructure of Sarcocystis Sporocysts from Passerine Birds and Opossums: Comments on Classification of the Genus Isospora
}

\author{
Edith D. Box \\ University of Texas Medical Branch \\ Alan A. Marchiondo \\ Brigham Young University \\ Donald W. Duszynski \\ University of New Mexico, eimeria@unm.edu \\ C. Patrick Davis \\ University of Texas Medical Branch
}

Follow this and additional works at: https://digitalcommons.unl.edu/parasitologyfacpubs

Part of the Parasitology Commons

Box, Edith D.; Marchiondo, Alan A.; Duszynski, Donald W.; and Davis, C. Patrick, "Ultrastructure of Sarcocystis Sporocysts from Passerine Birds and Opossums: Comments on Classification of the Genus Isospora" (1980). Faculty Publications from the Harold W. Manter Laboratory of Parasitology. 165. https://digitalcommons.unl.edu/parasitologyfacpubs/165

This Article is brought to you for free and open access by the Parasitology, Harold W. Manter Laboratory of at DigitalCommons@University of Nebraska - Lincoln. It has been accepted for inclusion in Faculty Publications from the Harold W. Manter Laboratory of Parasitology by an authorized administrator of DigitalCommons@University of Nebraska - Lincoln. 


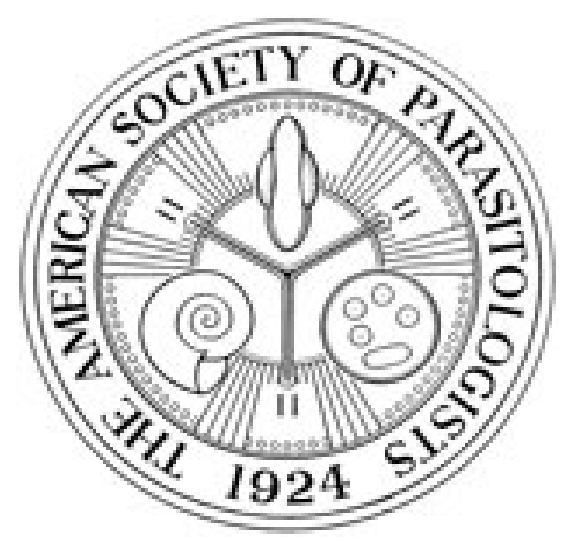

Ultrastructure of Sarcocystis Sporocysts from Passerine Birds and Opossums: Comments on Classification of the Genus Isospora

Author(s): Edith D. Box, Alan A. Marchiondo, Donald W. Duszynski, C. Patrick Davis

Source: The Journal of Parasitology, Vol. 66, No. 1 (Feb., 1980), pp. 68-74

Published by: The American Society of Parasitologists

Stable URL: http://www.jstor.org/stable/3280591

Accessed: 22/04/2010 01:22

Your use of the JSTOR archive indicates your acceptance of JSTOR's Terms and Conditions of Use, available at http://www.jstor.org/page/info/about/policies/terms.jsp. JSTOR's Terms and Conditions of Use provides, in part, that unless you have obtained prior permission, you may not download an entire issue of a journal or multiple copies of articles, and you may use content in the JSTOR archive only for your personal, non-commercial use.

Please contact the publisher regarding any further use of this work. Publisher contact information may be obtained at http://www.jstor.org/action/showPublisher?publisherCode=asp.

Each copy of any part of a JSTOR transmission must contain the same copyright notice that appears on the screen or printed page of such transmission.

JSTOR is a not-for-profit service that helps scholars, researchers, and students discover, use, and build upon a wide range of content in a trusted digital archive. We use information technology and tools to increase productivity and facilitate new forms of scholarship. For more information about JSTOR, please contact support@jstor.org.

The American Society of Parasitologists is collaborating with JSTOR to digitize, preserve and extend access to The Journal of Parasitology. 


\title{
ULTRASTRUCTURE OF SARCOCYSTIS SPOROCYSTS FROM PASSERINE BIRDS AND OPOSSUMS: COMMENTS ON CLASSIFICATION OF THE GENUS ISOSPORA
}

\author{
Edith D. Box, Alan A. Marchiondo, ${ }^{\star}$ Donald W. Duszynski, $\dagger$ and C. Patrick Davis \\ Department of Microbiology and Pathology, University of Texas Medical Branch, Galveston, Texas 77550
}

ABSTRACT: Sporocysts were obtained from the feces of opossums (Didelphis virginiana) which had been fed muscles of passerine birds (Molothrus ater and Cassidix mexicanus) infected with Sarcocystis. Sporocysts were examined by phase microscopy and scanning and transmission electron microscopy. Ridges on the surface of the sporocysts outlined four plates. Thin sections of the sporocyst wall showed thickened regions and gaps interpreted as cross sections of the ridges. The sporocyst wall has four major layers with a thick, granular inner layer which resembles the inner layer of sporocysts of related species. Excystation structures are discussed as a basis for classifying disporocystic coccidia to correlate with Frenkel's (1977) life cycle classification of this group.

Speer et al. (1973) reported ultrastructure of the sporocyst wall of Isospora canis and indicated that the wall consisted of four plates which separated during excystation, releasing the sporozoites. Later transmission electron microscope (TEM) studies on Isospora endocallimici (Speer et al., 1976) and on Toxoplasma gondii (Christie et al., 1978) provided evidence of the same phenomenon in related coccidia. Gaps between thickened areas in the sporocyst wall of Sarcocystis tenella, as described by Mehlhorn and Scholtyseck (1974), resembled points of apposition of plates seen in Isospora and Toxoplasma sporocysts. These genera belong to the group of cyst-forming coccidia of the Family Sarcocystidae (Frenkel, 1977). Actual conformation of the sporocyst plates only has been deduced by interpretation of TEM results (Speer et al., 1976). In the present study we examined the ultrastructural topography of sporocysts of passerine bird-opossum Sarcocystis using scanning electron microscopy (SEM) and the fine structure of the sporocyst wall by TEM.

\section{MATERIALS AND METHODS}

Sarcocystis sporocysts were obtained from two opossums infected with cysts from muscle from either cowbirds (Molothrus ater) or grackles (Cassidix mexicanus) by methods described previously (Duszynski and Box, 1978).

Received for publication 20 August 1979.

* Present address: Department of Zoology, Brigham Young University, Provo, Utah 84602.

† Present address: Department of Biology, The University of New Mexico, Albuquerque, New Mexico 87131.
Sporocysts in feces which had been mixed with $2.5 \%(\mathrm{w} / \mathrm{v}) \mathrm{K}_{2} \mathrm{Cr}_{2} \mathrm{O}_{7}$ and refrigerated for more than a year were concentrated by sugar flotation, washed, and fixed successively in $2.5 \%(\mathrm{v} / \mathrm{v})$ glutaraldehyde in $0.1 \mathrm{M}$ cacodylate buffer with $0.05 \%$ (w/v) $\mathrm{CaCl}_{2}$ (2 days, $5 \mathrm{C}$ ), $15 \%$ (v/v) glutaraldehyde in $0.1 \mathrm{M}$ cacodylate buffer with $0.05 \%(\mathrm{w} / \mathrm{v}) \mathrm{CaCl}_{2}$ (1 day, room temp.), and $15 \%(\mathrm{v} / \mathrm{v})$ glutaraldehyde in $0.2 \mathrm{M}$ cacodylate with $8 \%(\mathrm{w} / \mathrm{v})$ glucose $(18 \mathrm{hr}$, room temp.). The sporocysts then were dropped on coverslips coated with $0.1 \%(\mathrm{w} / \mathrm{v})$ poly-L-lysine, postfixed for $2 \mathrm{hr}$ in $1 \%(\mathrm{v} / \mathrm{v}) \mathrm{OsO}_{4}$ in $0.1 \mathrm{M}$ cacodylate buffer, dehydrated in ethanol, critical point dried, coated with gold/palladium by pulsing for 4 min in a Hummer II (Technics), and examined in an I.S.I. Super III Scanning Electron Microscope.

For TEM, a suspension of sporocysts was treated with $0.02 \mathrm{M}$ cysteine $\mathrm{HCl}$ followed by exposure to $\mathrm{CO}_{2}$ for $5 \mathrm{hr}$ at $40 \mathrm{C}$ and then to bile-trypsin (5\% [w/v] sodium glycocholate $+0.25 \%$ [w/v] trypsin) for $15 \mathrm{~min}$ at $40 \mathrm{C}$. The treated sporocyst suspension was densely packed by centrifugation in a solution consisting of $20 \%(\mathrm{w} / \mathrm{v})$ Bovine Serum Albumin (BSA) plus $15 \%(\mathrm{w} / \mathrm{v})$ sucrose in phosphate buffered saline, $\mathrm{pH}$ 7.4. A pellet was obtained by cross-linking the BSA treated sporocysts with $25 \%(\mathrm{v} / \mathrm{v})$ glutaraldehyde as described by Birch-Andersen et al. (1976). The sporocyst pellet was fixed in $15 \%$ (v/v) glutaraldehyde in $0.1 \mathrm{M}$ phosphate buffer for $12 \mathrm{hr}$ at $5 \mathrm{C}$ and postfixed in $2 \%(\mathrm{w} / \mathrm{v}) \mathrm{OsO}_{4}$ for $2 \mathrm{hr}$ at 22 C. The fixed pellet of sporocysts was rinsed several times in buffer, dehydrated in ethanol and two changes of propylene oxide, and embedded in Epon 812. Paraffin-embedded intestinal tissue from Sarcocystis infected opossums was prepared for TEM according to the methods described by Gonzalez-Angulo et al. (1978). Sections were placed on 200-mesh grids, stained with uranyl acetate and lead citrate, and examined with a Philips EM-201 transmission electron microscope.

To separate sporocyst wall plates for phase microscopy, washed sporocysts were suspended in a mixture of $0.25 \%(\mathrm{w} / \mathrm{v})$ trypsin and $5 \%(\mathrm{w} / \mathrm{v})$ sodium glycocholate, $\mathrm{pH} 7.6$, in phosphate buffered saline for $24 \mathrm{hr}$ at $40 \mathrm{C}$. 

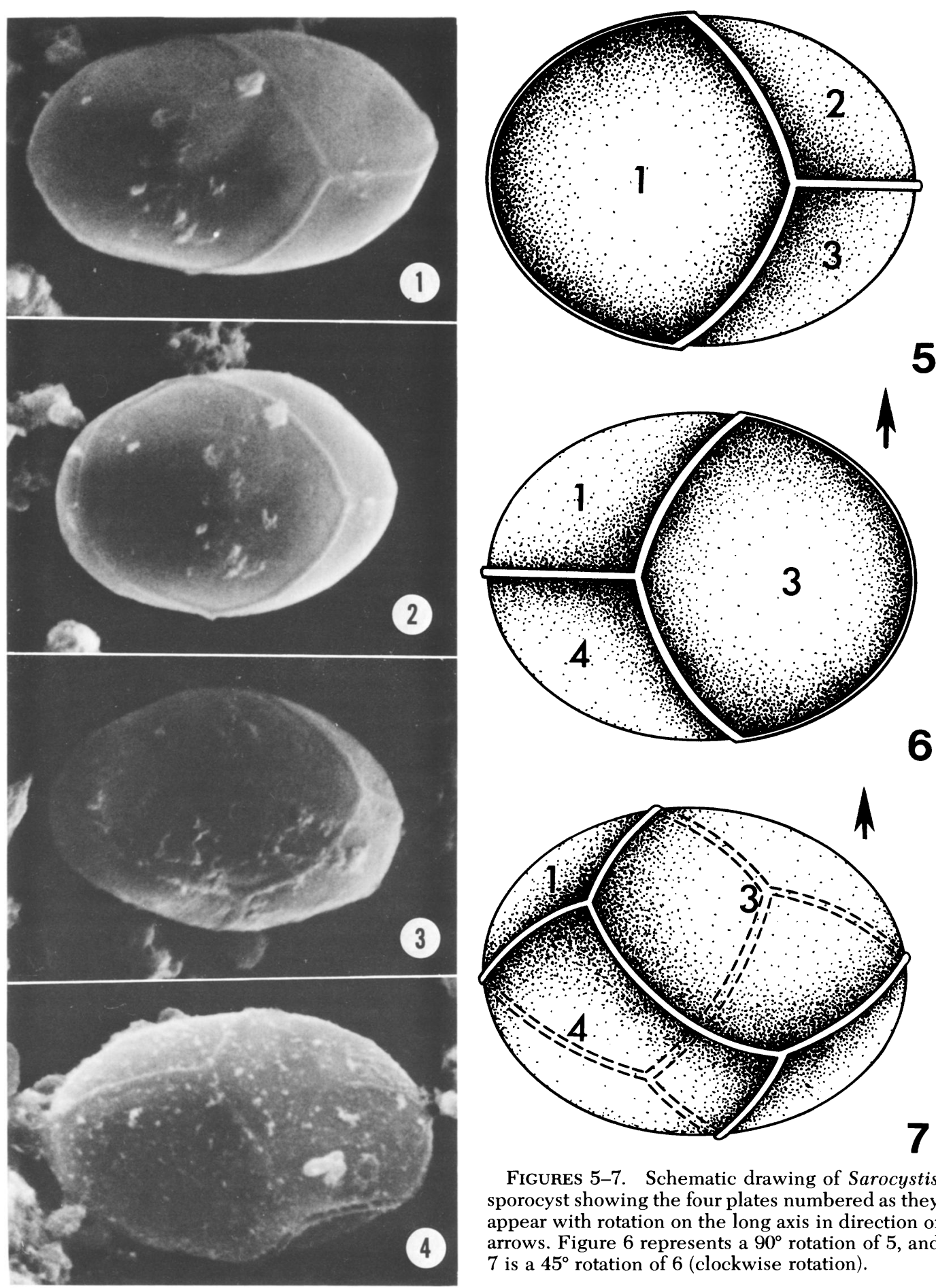

Figures 5-7. Schematic drawing of Sarocystis sporocyst showing the four plates numbered as they appear with rotation on the long axis in direction of arrows. Figure 6 represents a $90^{\circ}$ rotation of 5 , and 7 is a $45^{\circ}$ rotation of 6 (clockwise rotation).

Figures 1-4. Sporocysts as seen by SEM with raised lines marking the edge of the plates. $\times 46,000$. Figures 1 and 2 are the same sporocyst. In Figure 1 the stage was tilted $15^{\circ}$, in 2 the tilt was $40^{\circ}$. Figures 1,2 , and 3 are from the opossum in-

$\leftarrow$

fected from cowbirds, and 4 is from the opossum infected from grackles. 


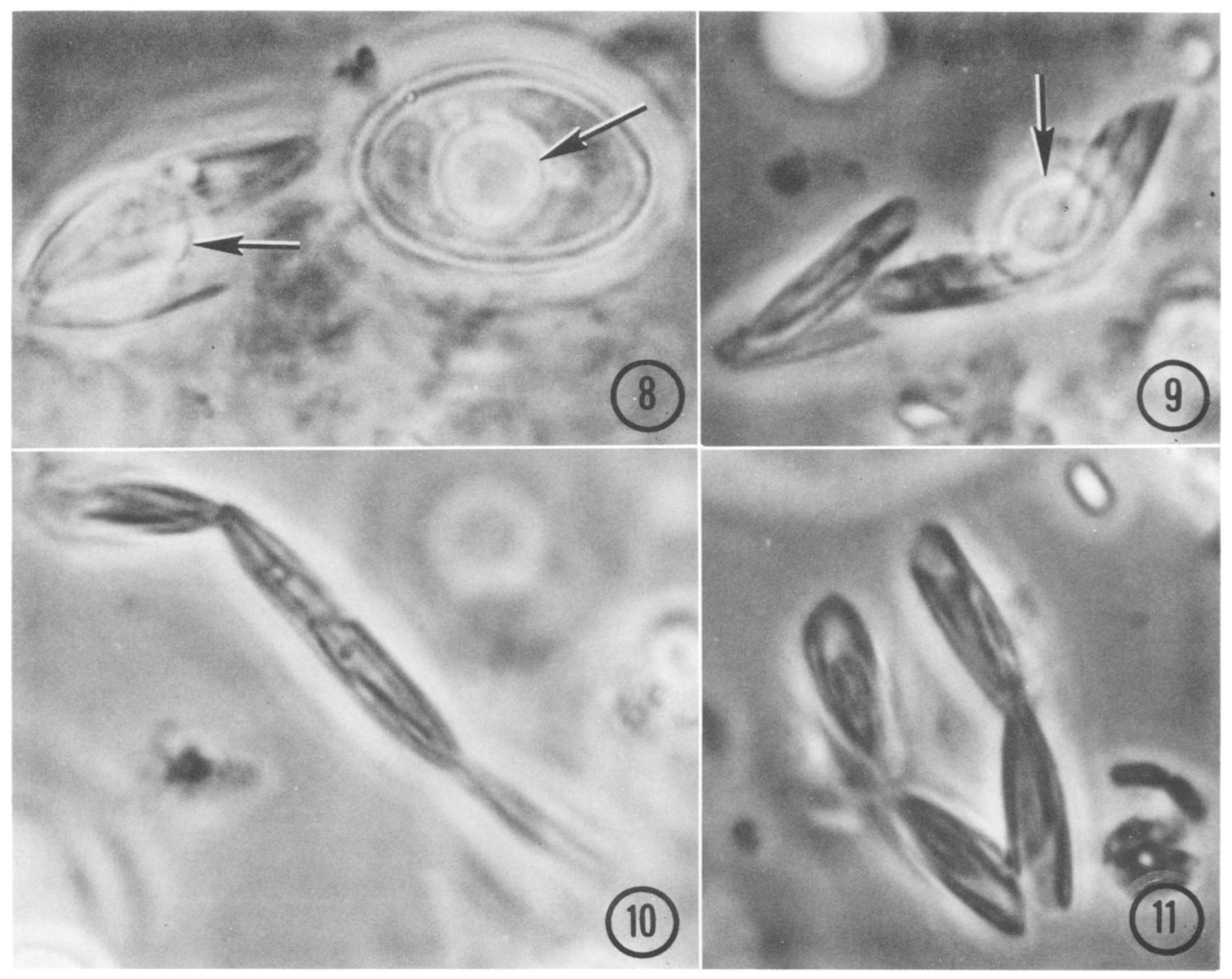

FiguRES 8-11. Separation of sporocyst plates after bile-trypsin treatment. $\times 3,000$ phase. Arrows $=$ residual body. 8. Intact sporocyst beside one with separated plates. 9. Two pairs of plates showing residual body in situ. 10. Two pairs of plates still joined at one middle suture. 11. Two separated pairs of plates showing pointed tips and rolled edges.

\section{RESULTS}

SEM photomicrographs showed raised lines on the surface of sporocysts (Figs. 1-4). The pattern was similar for sporocysts from the two opossums whether they were infected from cowbirds or grackles. A model was constructed of clay using photographs of several sporocysts for locating the lines. It was found that lines drawn as shown in the diagrams (Figs. 5-7) divided the sporocyst surface into four equal plates. By rotating the model, the pattern on it could be made to coincide with that seen on SEM photomicrographs (compare photomicrographs, Figs. $1-4$ and drawing, Figs. 5-7).

Examination by phase microscopy of sporocysts treated with bile-trypsin confirmed that the wall was made up of four plates which frequently separated in pairs at the center of the sporocyst. As shown in Figures 8-11, the edges of the plates were always rolled; commonly they were in pairs, but singles and strings of four also were found. The free ends of paired plates were pointed and the joined ends were held together at what had been the apex of the sporocyst.

Sections of sporocysts viewed with TEM showed sites of apposition of the walls with liplike thickenings (153-189 $\mathrm{nm}$ ) on each side of the cleavage (Figs. 12, 13). A thin strip of electron-dense material (18-27 $\mathrm{nm}$ ) interposed between the thickenings is seen adhering to the margin of one of the plates (Fig. 13).

The sporocyst wall is composed of four major layers in our preparation (Figs. 12-14). The outer layer apparently consists of one or two unit membranes embedded in a granular 


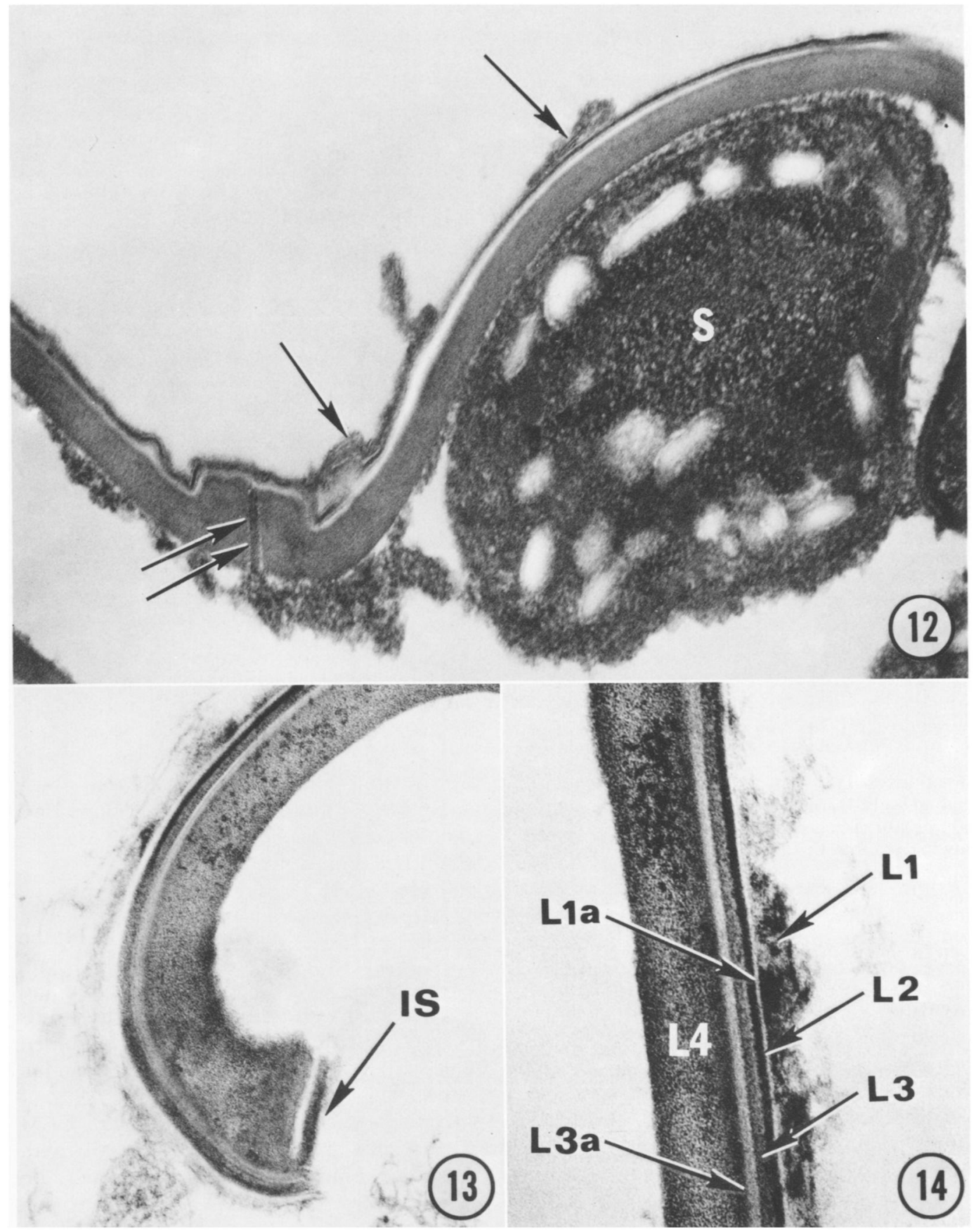

Figures 12-14. TEM of sporocyst wall. 12. Paraffin-embedded intestinal tissue. $\times 51,400$. Note unit membranes of outer layer (arrows), ridgelike site of apposition between two plates (double arrow) and sporozoite (S). 13. Site of apposition of sporocyst plates showing interposed strip (IS). $\times 90,000$. 14 . Sporocyst wall showing layers. Outer layer (L 1) containing unit membranes, layer 2 (L 2), layer 3 (L 3), and layer 4 (L 4). L 1a and L 3a correspond to relatively electron-lucent areas between layers. $\times 145,000$. 
electron-dense matrix of irregular thickness (14-107 nm, Figs. 12, 14). The nature of this material is unknown, but it seems unlikely to be an artifact, created, for example, by BSA because a granular appearance is also found on the SEM preparations which have not been exposed to BSA (compare Figs. 1-4 with Fig. 14). Layer 2 is osmiophilic and densely applied to the electron-lucent layer 3 (Fig. 14). Layers 2 and 3 measure 5.6 to $7.0 \mathrm{~nm}$ and 13.0 to $15.0 \mathrm{~nm}$, respectively. The inner layer (4) is relatively electron-lucent with a dense, coarsely granular matrix and measures 77 to $107 \mathrm{~nm}$. In addition there are two relatively electron-lucent areas; one (L 3a) separates layer 4 from layer 3, whereas another (L 1a) separates layer 1 from layer 2. Because they show poor staining characteristics, these two electron-lucent areas may be either additional layers that stain poorly or may be artifacts created during sample preparation.

\section{DISCUSSION}

The first SEM pictures of isosporid sporocysts published are those of a Sarcocystis species by Tombes (1979) who pictured sporocysts which he was using for controls in his SEM study of Giardia cysts. The sporocysts were described briefly as showing a slightly raised ribbing which is easily and consistently observed and which formed an oval hexahedron. The pattern in his photographs is similar to those found on our sporocysts, so that it seems unlikely that six plates were formed. We interpreted the raised surface lines forming patterns on sporocysts in our studies as representing margins of plates because the only interruptions in the sporocyst wall (as seen by TEM) are points of apposition of the plates similar to those identified in Isospora sporocysts by Speer et al. (1973, 1976). The division of Sarcocystis sporocysts into four plates agrees with the observations on Isospora as well as those on Toxoplasma (Christie et al., 1978). The shape of the plates of Sarcocystis is somewhat different from that postulated for $I$. endocallimici on the basis of TEM. The schematic diagram of the latter species (Speer et al., 1976) showed plates that come together at right angles at the midpoint of the sporocyst, whereas there are no right angles seen on the surface pattern of the Sarcocystis sporocyst. Such a difference in plate structure may provide an additional means of separating genera or even species in the Family Sarocystidae. The similar surface pattern found on sporocysts from opossums whether infected from cowbirds or grackles agrees with other evidence that these are the same species (Box and Duszynski, 1978).

We were unable to obtain TEM cross sections of intact walls because of the collapse of the sporocysts; however, the liplike thickenings we observed next to gaps in the sporocyst wall were similar to those described for two species of Isospora (Speer et al., 1973, 1976), for Toxoplasma (Christie et al., 1978), and S. tenella (Mehlhorn and Scholtyseck, 1974).

The fine structure of the sporocyst wall has been described for only a few species of coccidia. Our study demonstrates four major layers for the sporocyst wall of Sarcocystis sp. (passerine bird-opossum) plus two electronlucent areas which could not be identified as layers. In comparison, S. tenella, I. canis, and I. endocallimici have been interpreted as having two prominent layers and $T$. gondii, five layers. The sporocyst walls of these species all have in common a relatively thick electron-dense inner layer. In contrast, $\mathrm{Ei}$ meria nieschulzi (Marchiondo et al., 1978) and E. falciformis (Marchiondo, unpublished observation) possess a thin sporocyst wall composed of three to four tightly bound unit membranes with no interruptions except at the Stieda body.

The similarities of structure with four collapsible plates reported for sporocysts of species of Isospora, Toxoplasma, and Sarcocystis correlate with Frenkel's classification (1977) of the coccidia. He created the Family Sarcocystidae to separate heteroxenous coccidia with tissue cysts from the Family Eimeriidae which are monoxenous. Historically, classification has been based on the number of sporocysts per oocyst in which all coccidia with four sporocysts and two sporozoites each were called Eimeria, and those with two sporocysts and four sporozoites each were Isospora; both genera were in the Family Eimeriidae.

A more important feature than number of sporocysts in classification appears to be excystation structures because they correlate with life cycle. As first pointed out by Speer et al. (1973), some Isospora spp. excyst by collapse of plates, whereas other Isospora excyst 
by escape of sporozoites through an opening in the sporocyst plugged by a Stieda body. In coccidia of warm-blooded vertebrates for which the life cycle is known, both Eimeria and Isospora with Stieda bodies in the sporocyst have one host, whereas Isospora spp. which excyst by dissolution of plates have two hosts.

A close relationship of Isospora having Stieda bodies and Eimeria is suggested by a recent study by Norton and Joyner (1978), who found that oocysts of Eimeria maxima of the chicken contained four sporocysts, but this was reduced to two sporocysts during chemotherapy. By selection, they were able to obtain a yield of about $80 \%$ "Isospora" type oocysts which were fully viable.

Toxoplasma gondii and Sarcocystis spp. with life cycles involving two hosts have been observed to excyst by collapse of sporocyst plates. Dubey (1975) showed that I. canis, the first species found to have sporocyst plates, is facultatively heteroxenous. The life cycle of I. endocallimici is unknown, but a similar (if not the same) primate species, Isospora arctopithici, which also excysts by separation of plates (Duszynski and Speer, 1976), is reported to be facultatively heteroxenous (Hendricks and Walton, 1974). Evidence of the same type of excystation has been obtained by light microscopy for Sarcocystis species. Fayer and Leek (1973) reported that S. fusiformis sporocysts from dogs excysted via a transverse break in the wall. Similarly, Duszynski and Speer (1976) found that Isospora bigemia (Sarcocystis sp.) excysted by separation of the sporocyst wall. The opossumpasserine Sarcocystis sporocysts in our studies also have walls with four plates that separate during excystation.

Because mode of excystation and structure of sporocysts can be correlated with Frenkel's classification according to life cycle, it is suggested that Isospora be retained as a genus name for coccidia with disporocystic oocysts and sporocysts with a Stieda body. The Family Eimeriidae would include coccidia of warm-blooded animals with Stieda bodies in the sporocysts, i.e., Eimeria and Isospora. Disporocystic coccidia without a Stieda body would be classified in the Family Sarcocystidae. The genera would include Cystoisospora, Toxoplasma, Sarcocystis, Besnoitia, Frenkelia, and Hammondia (see Frenkel,
1977) based on our current understanding of the life cycle.

Sporocyst structure should be considered as an important indicator of taxonomic relationships and may be useful in rearrangement of other groups of coccidia. For example, Lom (1971) described sporocysts of species of fish Eimeria without Stieda bodies but with two sutures ultrastructurally resembling those of the Sarcocystidae. He pointed out that similar bivalve sporocysts occur also in the genera Cyclospora, Barrouxia, Urobarrouxia, and Aggregata. Possibly many genera based on number of sporocysts per oocyst are more artificial than real.

\section{LITERATURE CITED}

Birch-ANDERsen, A., D. J. P. Ferguson, AND R. D. Pontefract. 1976. A technique for obtaining thin sections of coccidian oocysts. Acta Pathol Microbiol Scand Sect B 84: 235-239.

Box, E. D., AND D. W. DuszynskI. 1978. Experimental transmission of Sarcocystis from icterid birds to sparrows and canaries by sporocysts from the opossum. J Parasitol 64: 682-688.

Christie, E., Pappas, P. W., AND J. P. Dubey. 1978. Ultrastructure of excystment of Toxoplasma gondii oocysts. J Protozool 25: 438443.

DuBEY, J. P. 1975. Experimental Isospora canis and Isospora felis infection in mice, cats and dogs. J Protozool 22: 416-417.

Duszynski, D. W., AND E. D. Box. 1978. The opossum (Didelphis virginiana) as a host for Sarcocystis debonei from cowbirds (Molothrus ater) and grackles (Cassidix mexicanus, Quiscalus quiscula). J Parasitol 64: 326-329.

- AND C. A. SPEER. 1976. Excystation of Isospora arctopitheci Rodhain, 1933 with notes on a similar process in Isospora bigemina (Stiles, 1891) Luhe, 1906. Z Parasitenkd 48: 191-197.

FAYER, R., AND R. G. LEEK. 1973. Excystation of Sarcocystis fusiformis sporocysts from dogs. Proc Helminthol Soc Wash 40: 294-296.

Frenkel, J. K. 1977. Besnoitia wallacei of cats and rodents: With a reclassification of other cystforming isosporoid coccidia. J Parasitol 63: 611-628.

Gonzales-Angulo, A., I. R. DE Chavez, And M. CASTANEDA. 1978. A reliable method for electron microscopic examination of specific areas from paraffin-embedded tissue mounted on glass slides. Am J Clin Pathol 70: 697-699.

Hendricks, L. D., AND B. C. Walton. 1974. Vertebrate intermediate hosts in the life cycle of an isosporan from a non-human primate. Proc 3rd Int Congr Parasitol Muenich. Facta Publications 1: 96-98.

LOM, J. 1971. Remarks on the spore envelopes in fish coccidia. Folia Parasitol Prague 18: 289293.

Marchiondo, A. A., D. W. Duszynski, AND C. A. 
SPEER. 1978. Fine structure of the oocyst wall of Eimeria nieschulzi. J Protozool 25: 434-437. Licht- und elektronenmikroskopische Untersuchungen an Entwicklungsstadien von Sarcocystis tenella aus der Darmwand der Hauskatze. I. Die oocysten und sporocysten. Z Parasitenkd 43: 251-270.

Norton, C. C., AND L. P. Joyner. 1978. The appearance of bisporocystic oocysts of Eimeria maxima in drug-treated chicks. Parasitology 77: 243-248.
MeHLhORN, H., AND E. SChOLTYSECK. 1974.

Speer, C. A., D. M. HAMmond, J. L. MAHrT, AND W. L. RoberTs. 1973. Structure of the oocyst and sporocyst walls and excystation of sporozoites of Isospora canis. J Parasitol 59: 35-40.

, A. A. Marchiondo, D. W. DuszYnSKI, AND S. K. FILE. 1976. Ultrastructure of the sporocyst wall during excystation of Isospora endocallimici. J Parasitol 62: 984-987.

Tombes, A. S. 1979. Surface morphology of Giardia cysts recovered from a variety of hosts. In W. Jakubowski and J. C. Hoff (eds.), Waterborne transmission of giardiasis. EPA 600/9-79-001, June 1979, pp. 22-37.

J. Parasitol., 66(1), 1980, p. 74 (C) American Society of Parasitologists 1980

\section{BOOK REVIEW . . .}

Advances in Parasitology, edited by W. H. R. Lumsden, R. Muller, and J. R. Baker. Academic Press, 1978. Vol. 16, 376 p. $\$ 35.75$.

In these days of rising costs and reduced budgets, literary "dinosaurs" rapidly will become extinct; thus it is good to see the series started by Ben Dawes continue in the able hands of W. H. R. Lumsden. At a time when parasitologists feel the need for some introspective appraisal and self criticism, it is gratifying to be able to turn to reviews of high standard for a concise synthesis of current thought. One expects that, in future numbers, the material will reflect changing emphasis, but one hopes that it doesn't become too heavily committed to subject matter which may already be well covered elsewhere.

The current volume opens with a comprehensive review of taxonomic problems and transmission of Leishmanial parasities by Williams and Coelho. Among a number of topics, they discuss new methods used to try to resolve the problem of morphological similarities of Leishmania infective to man, but which produce different pathological lesions. Much emphasis is placed on the phlebotomine hosts of Leishmania and other genera of Trypanosomatidae, describing a variety of experimental and naturally occurring infections in Phlebotomus and Lutzomyia.

The Sarcosporidia are discussed concisely and clearly by Melhorn and Heydorn who concentrate mainly on Sarcocystis. The structure, life cycle, and distribution of the group are considered, and fine structural details are illustrated in a series of electron micrographs and well-prepared charts.

The marine nematode Anisakis and the disease syndrome Anisakiasis is reviewed comprehensively by Smith and Wooten, who cover taxonomy, life history, and pathology of members of the genus in a variety of hosts including fish, marine mammals, and man.

Prospects for the development of dead vaccines against helminths are discussed by Clegg and Smith in a well balanced and pertinent review. Material pertaining to vaccination against nematodes, cestodes, and trematodes, primarily the schistosomes, is presented. It is a pity, however, that in considering this important topic they did not stress the relevant problems of hypersensitivity and actual delivery of the vaccines in endemic areas, a matter highlighted by the final review in the book.

Genetic control of susceptibility and resistance to parasitic infection is reviewed well by Wakelin. The subject matter, confined to animal host-parasite relationships, extends from invertebrate hosts such as snails and mosquitoes to variations in host response to infections of trypanosomes, plasmodia, and metazoal parasites.

The book ends with two short reviews, the regulation of respiratory mechanism in parasitic helminths by Bryant, and the sad state of the industrial development and field use of canine hookworm vaccine by Miller. This latter paper sounds a warning note to those of us eagerly embarking on the development of antihelminth vaccines.

As with others in the series, the book is well produced, well indexed, clear, and accurate. It represents a significant addition to the series.

C. J. Shiff, Laboratory of Nuclear Medicine, The University of California, Los Angeles, California 90024. 